\section{Commentary: Back to the future: Failed mitral valve bioprosthesis in the setting of mitral annular calcification}

\author{
Nathaniel Parchment, MD, \\ Alexander A. Brescia, MD, MSc, and \\ Gorav Ailawadi, MD
}

Falasa and colleagues ${ }^{1}$ present a case of mitral valve-invalve (MViV) replacement in a patient with traumatic injuries who 8 years previously had an intra-atrial $25 \mathrm{~mm}$ Edwards pericardial mitral valve replacement (MVR) with a Dacron conduit due to extensive mitral annular calcification (MAC). ${ }^{1}$ The authors should be applauded for innovative use of MViV with non-conventional anatomy and high surgical risk. Intra-atrial MVR is uncommon; however, a few technical points deserve mention.

Transeptal puncture must be altered from a conventional MViV (2 $\mathrm{cm}$ posterolateral to typical location), given the supra-annular prosthetic height and difficulty gaining height with the Edwards delivery system. Posterior bias on the septum remains critical for alignment. Second, navigating across stenotic valves typically requires a steerable guide as used here, facilitated by intraoperative 3dimensional echocardiography. Finally, given the atrialization of the prosthesis, the risk of left ventricular outflow tract obstruction is low.

Another important consideration relates to patientprosthesis mismatch. The patient originally received a 25-mm mitral prosthesis. In large analyses of the Valvein-Valve International Data (VIVID) Registry, MViV with

\footnotetext{
From the Department of Cardiac Surgery, University of Michigan, Ann Arbor, Mich. Disclosures: Dr Ailawadi is a consultant for Abbott, Edwards, Medtronic, Anteris, Gore, and AtriCure. All other authors reported no conflicts of interest.

The Journal policy requires editors and reviewers to disclose conflicts of interest and to decline handling or reviewing manuscripts for which they may have a conflict of interest. The editors and reviewers of this article have no conflicts of interest.

Received for publication Aug 2, 2021; revisions received Aug 2, 2021; accepted for publication Aug 3, 2021; available ahead of print Aug 6, 2021.

Address for reprints: Gorav Ailawadi, MD, Department of Cardiac Surgery, University of Michigan, 1500 E Medical Center Dr, CVC 5153, Ann Arbor, MI 48109 (E-mail: ailawadi@med.umich.edu).

JTCVS Techniques 2021;10:269-70

2666-2507

Copyright (C) 2021 The Author(s). Published by Elsevier Inc. on behalf of The American Association for Thoracic Surgery. This is an open access article under the CC BY-NC-ND license (http://creativecommons.org/licenses/by-nc-nd/4.0/).

https://doi.org/10.1016/j.xjtc.2021.08.007
}

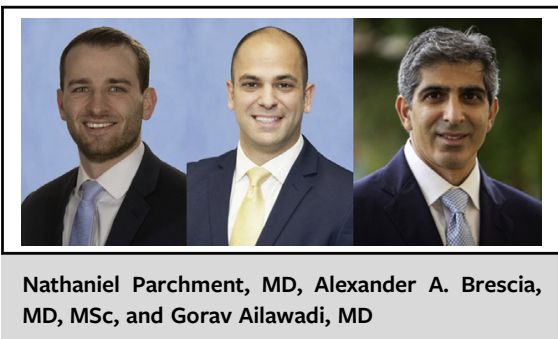

CENTRAL MESSAGE

This report highlights the safety of transcatheter MViV, even with challenging anatomy. It emphasizes that we need to consider lifetime management to optimize future interventions.

$27 \mathrm{~mm}$ or smaller surgical valves increased risk of postprocedural stenosis and early failure. Subsequently, residual mitral stenosis carried a significantly greater risk of repeat $\mathrm{MVR}^{2}$

The intra-atrial/nonannular mitral replacement also raises considerations. The goals of annular debridement of MAC are to (1) create a safe annulus for suture placement/valve seating and (2) create good left ventricular inflow by debriding sufficient mitral valve to avoid stenosis. Moreover, in patients with MAC or rheumatic mitral stenosis, we advocate aggressive debridement of the papillary muscles to minimize the risk of recurrent subvalvular stenosis. ${ }^{3}$ With the approach taken at the initial operation in this case, there remains risk of stenosis at the native annulus and subvalvular level, which would manifest as early prosthetic failure. No universal surgical approach to MAC has been accepted. Techniques range from complete resection and removal of all calcification, ${ }^{4}$ to using ultrasonic emulsification and aspiration of $\mathrm{MAC},{ }^{5}$ to placing a prosthesis in the left atrium as in this case, to bypassing the valve entirely with an external conduit. ${ }^{6}$

Given surgeons trepidation to aggressively debride MAC, other options have emerged, including: (1) percutaneous valve-in-MAC (ViMAC), (2) surgically deployed balloon expandable SAPIEN ViMAC, ${ }^{7}$ and (3) Tendyne-in-MAC. ${ }^{8}$ A 100-patient cohort who underwent ViMAC experienced significantly lower success rates compared with MViV $(74 \%$ vs $91 \%, P<.001)$. ViMAC experienced a $10 \%$ rate of left ventricular outflow tract obstruction and 30 -day mortality of $21.8 \%$, both lower than previously reported rates for ViMAC, but significantly greater than the 
MViV cohort. ${ }^{2}$ Surgical transatrial deployment of balloon expandable valves can minimize left ventricular outflow tract obstruction risk by debridement of the anterior leaflet and septum. ${ }^{9}$ Finally, there is great enthusiasm for the Tendyne transcatheter valve in MAC due to report of 9 compassionate use cases, with only one mortality at 12-month follow-up despite a transapical approach. ${ }^{10}$

In summary, this report highlights the safety of transcatheter MViV, even with challenging anatomy. It also emphasizes that we, as surgeons, need to consider lifetime management to optimize future interventions, including adequate debridement, larger prostheses, and continued innovation.

\section{References}

1. Falasa MP, Tartara P, Matar R, Jones TE, Anderson RD, Beaver TM. Transseptal mitral valve-in-valve replacement of intra-atrial mitral prosthesis in a patient with severe mitral annular calcification. J Thorac Cardiovasc Surg Tech. 2021; 10:266-8.

2. Guerrero M, Vemulapalli S, Xiang Q, Wang DD, Eleid M, Cabalka AK, et al. Thirty-day outcomes of transcatheter mitral valve replacement for degenerated mitral bioprostheses (valve-in-valve), failed surgical rings (valve-in-ring), and native valve with severe mitral annular calcification (valve-in-mitral annular calcification) in the United States: data from the Society of Thoracic Surgeons/ American College of Cardiology/Transcatheter Valve Therapy Registry. Circ Cardiovasc Interv. 2020;13:e008425.

3. Kessel SM, Hawkins RB, Yarboro LT, Ailawadi G. Total chordal sparing mitral valve replacement in rheumatic disease: a word of caution. Ann Thorac Surg. 2017;104:e47-8.

4. Feindel CM, Tufail Z, David TE, Ivanov J, Armstrong S. Mitral valve surgery in patients with extensive calcification of the mitral annulus. J Thorac Cardiovasc Surg. 2003;126:777-82.

5. Uchimuro T, Fukui T, Shimizu A, Takanashi S. Mitral valve surgery in patients with severe mitral annular calcification. Ann Thorac Surg. 2016;101:889-95.

6. Said SM, Schaff HV. An alternate approach to valve replacement in patients with mitral stenosis and severely calcified annulus. J Thorac Cardiovasc Surg. 2014; 147:e76-8.

7. Guerrero M, Urena M, Himbert D, Wang DD, Eleid M, Kodali S, et al. 1-year outcomes of transcatheter mitral valve replacement in patients with severe mitral annular calcification. J Am Coll Cardiol. 2018;71:1841-53.

8. Dahle G. Current devices in TMVI and their limitations: focus on Tendyne. Front Cardiovasc Med. 2020;7:592909.

9. Smith RL, Hamandi M, Ailawadi G, George TJ, Mack MJ, DiMaio JM, et al. BEV-in-MAC Collaborative. Surgical implantation of balloon-expandable heart valves for the treatment of mitral annular calcification. JTCVS. 2021.

10. Sorajja P, Gössl M, Babaliaros V, Rizik D, Conradi L, Bae R, et al. Novel transcatheter mitral valve prosthesis for patients with severe mitral annular calcification. J Am Coll Cardiol. 2019;74:1431-40. 